nặng, thể hiện mức độ nặng của trầm cảm.

TÀI LIẸU THAM KHẢO

1. RAFEi $H$, El-Bahesh E, FiNiANOS A, NASSEREDDiNE S, Tabbara I. Immune-based Therapies for Non-small Cell Lung Cancer. AR. 2017:37(2):377-388.

doi:10.21873/anticanres.11330

2. Brown CG, Brodsky J, Cataldo JK. Lung Cancer Stigma, Anxiety, Depression and Quality of Life. J Psychosoc Oncol. 2014;32(1):59-73. doi:10.1080/07347332.2013.855963

3. Hong JS, Tian J. Prevalence of anxiety and depression and their risk factors in Chinese cancer patients. Support Care Cancer. 2014;22(2):453459. doi:10.1007/s00520-013-1997-y

4. Massie MJ. Prevalence of Depression in Patients With Cancer. Journal of the National Cancer
Institute Monographs. 2004:2004(32):57-71. doi:10.1093/jncimonographs/lgh014

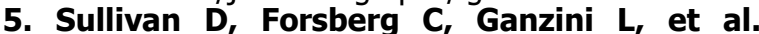
Depression Symptom Trends and Health Domains among Lung Cancer Patients in the CanCORS Study. Lung Cancer. 2016;100:102-109. doi:10.1016/j.lungcan.2016.08.008

6. Arrieta Ó, Angulo LP, Núñez-Valencia $C$, et al. Association of Depression and Anxiety on Quality of Life, Treatment Adherence, and Prognosis in Patients with Advanced Non-small Cell Lung Cancer. Ann Surg Oncol. 2013;20(6):1941-1948. doi:10.1245/s10434-012-2793-5

7. Sullivan DR, Ganzini L, Duckart JP, et al. Treatment Receipt and Outcomes among Lung Cancer Patients with Depression. Clinical Oncology. 2014;26(1):25-31. doi:10.1016/j.clon.2013.09.001

\title{
ĐĂC ĐIỂM LÂM SÀNG, CẬN LÂM SÀNG VÀ TÍNH NHẠY CẢM KHÁNG SINH CỦA STREPTOCOCCUS PNEUMONIAE GÂY VIÊM PHỔI CộNG ĐỒNG Ở' TRẺ EM DƯỚI 5 TUỔI TẠI BỆNH VIỆN SẢN NHI NGHỆ AN
} Bùi Anh Sơn*, Lê Thị Minh Hằng*, Nguyễn Thị Thúy Hằng*

\section{TÓM TẮT}

Mục tiêu: Mô tả đặc điểm lâm sàng, cận lâm sàng của viêm phổi cộng đồng do Streptococcus Pneumoniae (S.Pneumoniae) và mô tả tính nhạy cảm kháng sinh của các chủng S.Pneumoniae phân lập được ở trẻ dưới 5 tuổi bị viêm phổi cộng đồng tại bệnh viện Sản Nhi Nghệ An. Đối tượng và phương pháp nghiên cứu: Mố tả tiến cứu, 65 bênh nhân dưới 5 tuổi đủ tiêu chuẩn chẩn đoán viêm phổi cộng đồng do S.Pneumoniae điều trị tại Bệnh viện Sản Nhi Nghệ An từ 1/2021 - 9/2021 được nghiên cứu, mô tả đặc điểm lâm sàng và cận lâm sàng của viêm phổi, xác định tính nhạy cảm kháng sinh bằng đo nồng đố ức chế tối thiểu (MIC). Kết quả và kêt luận: Tỷ lể bệnh nhân Nam/Nữ là:1,9/1. Lứa tuổi hay gặp nhất là 2 tháng - 24 tháng với tỷ lệ $76,9 \%$. Tỷ lệ bệnh nhân đã dùng kháng sinh trước và̀o viện cao, chiếm $64,6 \%$. Các triệu chứng như sốt, ho, chảy nước mũi, thở nhanh, phổi có ran gặp tỳ lệ > 69\%. Xét nghiệm chủ yếu dựa vào Xquang tim phổi, công thức máu, CRP và nuôi cấy dịch tỵ hầu làm kháng sinh đồ. Viêm tai giữa ứ mủ gặp 43,1\%. S.Pneumoniae kháng với Azithromycin, Clarithromycin, Erythromycin là 100\%; kháng với Cefotaxime là $61,5 \%$, Ceftriaxone là 52,3\%, Penicillin là $18,5 \%$. S.Pneumoniae còn nhạy $100 \%$ với Rifampicin, Vancomycin, Linezolid, Levofloxacin.

Tư khóa: Streptococcus Pneumoniae, phễ cầu, viêm phổi, kháng kháng sinh, trẻ em.

*Bệnh viện Sản Nhi Nghê An

Chịu trách nhiệm chính: Bùi Anh Sơn

Email: drsonres@gmail.com

Ngày nhận bài: 2.8.2021

Ngày phản biên khoa học: 1.10.2021

Ngày duyệt bài: 6.10 .2021

\section{SUMMARY \\ CLINICAL, SUBCLINICAL TESTS \\ CHARACTERISTICS AND ANTIMICROBIAL \\ OF STREPTOCOCUS PNEUMONIAE THAT \\ CAUSING COMMUNITY ACQUIRED \\ PNEUMONIAE IN CHILDREN UNDER 5 \\ YEARS OLD AT NGHE AN OBSTETRICS AND PEDIATRICS HOSPITAL}

Objective: Describe clinical, subclinical tests characteristics, antibiotic resistance of S.Pneumoniae in children under 5 years old at Nghe An Obstetrics and Pediatrics Hospital. Patiens and Method: Prospective, cross sectional descriptive study in children under 5 years old, 65 patients with S.Pneumoniae pneumonia at Nghe An Obstetrics and Pediatrics Hospital include study, review clinical and subclinical tests characteristics, determine antimicrobial susceptibility by measuring the minium inhibitory concentration (MIC). Results and conclusions: The proportion of patients with Pneumococcal pneumonia in boys/girls was $1,9 / 1$. The most common age group was from 12 - 24 months old with rate of $76,9 \%$. The proportion of patients who had taken antibiotics before being hospitalized was high, accouting for $64,6 \%$. Clinical manifestations: cough, fever, running nose, tachypenia, rale were $>$ $69 \%$. The important subclinical tests in diagnosing and treating were chest Xrays, blood count, CRP and culture of nasopharyngeal fluid. The proportion of patients who had acute otitis media was $43,1 \%$. S.Pneumoniae was resistant to Azithromycin, Clarithromycin, Erythromycin in the rate of $100 \%$. S.Pneumoniae was resistant to Cefotaxime in the rate of $61,5 \%$, with Ceftriaxone was $52,3 \%$, with Penicillin was $18,5 \%$. S.Pneumoniae is also sensitive to 
Rifampicin, Vancomycin, Linezolid, Levofloxacin (100\%). Keywords: Streptococcus Pneumoniae, Pneumonia, resistant antibiotic, children.

\section{I. ĐĂT VẤN ĐỀ}

Viêm phổi là một trong những căn nguyên chính gây ra tử vong ở trẻ em dưới 5 tuổi trên toàn thế giới. Mỗi năm, bệnh lý này gây ra cái chết cho $15 \%$ trẻ em trên toàn cầ, $50 \%$ trẻ em tại Châu Phi vùng cận sa mạc Sahara [1]. Ở Việt Nam viêm phổi cũng là bệnh đứng hàng đâu về tỷ lệ mắc bệnh và tử vong ở trẻ em dưới 5 tuổi. Theo Đăng Đức Anh, trong nhiễm khuẩn hô hấp cấp tính ở trẻ em dưới 5 tuổi, tỷ lệ phân lập được vi khuẩn là $41.9 \%$, trong đó S.Pneumoniae chiếm 38.5\%[2]. Biểu hiện lâm sàng thường gặp của viêm phổi là ho, sốt, thở nhanh. Trường hợp nặng có thể tím tái, ngừng thở, khám có thể thây hội chứng ba giảm, đông đặc.... Viêm phổi do S.Pneumoniae có thể điều trị khỏi bằng kháng sinh nhưng việc điều trị ngày càng khó khăn hơn do vi khuẩn kháng thuốc. Hậu quả là kéo dài thời gian nằm viện, tăng tỷ lệ tử vong, tăng chi phí cho y tế, là gánh nặng cho gia đình và xã hội. Vì vậy, câu hỏi đặt ra là liệu đăc điểm viêm phổi do S.Pneumoniae ở trẻ em dưới 5 tuổi và tính nhạy cảm cũng như tính kháng kháng sinh của S.Pneumoniae ở đối tượng này như thể nào để từ đó mỗi cơ sở y tế đưa ra được phác đồ điều trị hiệu quả nhất. Vì vậy, để trả lời câu hỏi trên chúng tôi đã tiến hành nghiên cứu: Mô tả đặc điểm lâm sàng, cận lâm sàng và tính nhay cảm kháng sinh của Streptococcus Pneumoniae gây viêm phôi công đồng ở trẻ em dưới 5 tuổi tại Bệnh viện Sản Nhi Nghệ An.

\section{II. ĐỐI TƯỢNG VÀ PHƯƠNG PHÁP NGHIÊN CỨU}

Thời gian nghiên cứu: Từ tháng 1 năm 2021 đến tháng 9 năm 2021.

Địa điểm nghiên cứu: Khoa Hô hấp, Khoa hồi sức cấp cứu Nội khoa và khoa hồi sức cấp cứu Ngoại của Bệnh viện Sản Nhi Nghệ An.

\section{Đối tượng nghiên cứu:}

Tiêu chuân chọn bênh nhân: Các bênh nhân viêm phổi cộng đồng nhập viện từ 1 tháng đến dưới 5 tuổi được chẩn đoán là viêm phổi cộng đồng và có kết quả nuôi cấy dịch tỵ hầu dương tính với S.Pneumoniae.

- Chẩn đoán viêm phổi cộng đồng dựa vào tiêu chuẩn lâm sàng của Tổ chức $Y$ tế thế giới và kết quả chụp Xquang phổi.

Phương pháp nghiên cứu: mô tả.

- Thiết kế nghiên cứu: Nghiên cứu tiến cứu

- Bệnh nhân vào viện được khám lâm sàng, làm các xét nghiệm cần thiết, chụp Xquang phổi, khám tai mũi họng và cấy dịch tỵ hầu ngay sau khi được chẩn đoán là viêm phổi cộng đồng.

- Các biến số và chỉ số nghiên cứu: Tuổi, giới, tiền sử điều trị kháng sinh trước vào viện, bạch cầu, CRP, xquang tim phổi, kết quả khám tai mũi họng và kết quả kháng sinh đồ.

- Kỹ thuật phân lập vi khuẩn: Sử dụng phương pháp cấy đếm theo quy trình, kết quả cấy dương tính khi phân lập được vi khuẩn gây bệnh với số lượng $\geq 10^{6} \mathrm{CFU} / \mathrm{ml}$.

- Xác định tính nhay cảm kháng sinh của S.Pneumoniae: Dùng phương pháp đo MIC, đo độ đục để theo dõi sự phát triển của vi sinh vật trong các giếng của card với các chủng S.Pneumoniae phân lập được. Cho kết quả theo các mức độ: $\mathrm{S}$ (Sensitive): Nhay; I (Intermediate): Trung gian; R (Resistance): Kháng.

Phân tích và xử lí số liệu: Số liệu được xử lý theo thuật toán thống kê trên máy tính bằng phần mềm SPSS 20.

\section{KẾT QUẢ NGHIÊN CứU}

Trong thời gian nghiên cứu chúng tôi có 65 bệnh nhân viêm phổi đủ tiêu chuẩn đưa vào nghiên cứu và xác định được tính nhạy cảm kháng sinh của S.Pneumoniae .

Bảng 3.1. Một số đặc điểm của đôî tượng nghiên cứu

\begin{tabular}{|c|c|c|c|}
\hline \multicolumn{2}{|c|}{ Đặc điểm } & n & $\begin{array}{c}\text { Tỷ lệ } \\
(\%)\end{array}$ \\
\hline \multirow{2}{*}{ Giới } & Nam & 43 & 66,2 \\
\cline { 2 - 4 } & Nữ & 22 & 33,8 \\
\hline \multirow{2}{*}{$\begin{array}{c}\text { Nhóm } \\
\text { tuổi }\end{array}$} & Dưới 2 tháng tuổi & 6 & 9,2 \\
\cline { 2 - 4 } & 2 tháng-dưới 24 tháng & 50 & 76,9 \\
\cline { 2 - 4 } & 24 tháng - 60 tháng & 9 & 13,9 \\
\hline
\end{tabular}

Nhận xét: Viêm phối do S.Pneumoniae gặp nhiều nhất ở nhóm tuổi 2 tháng - dưới 24 tháng $(76,9 \%)$, trẻ dưới 2 tháng ít gặp viêm phổi do S.Pneumoniae cộng đồng $(9,2 \%)$. Tỷ lệ Nam/Nữ là $1,9 / 1$.

Bảng 3.2. Tiền sử dụng kháng sinh trước khi nhập viện

\begin{tabular}{|c|c|c|c|c|}
\hline $\begin{array}{l}\text { Điêu trị } \\
\text { kháng } \\
\text { sinh }\end{array}$ & $\begin{array}{l}\text { Loại kháng } \\
\text { sinh }\end{array}$ & $\begin{array}{c}\text { Số } \\
\text { lượng }\end{array}$ & $\begin{array}{l}\text { Tỷ lệ } \\
(\%)\end{array}$ & Tổng \\
\hline \multirow{3}{*}{ Đã dùng } & $\begin{array}{c}\text { Amoxcicilin/ } \\
\text { Amoxcicilin+ } \\
\text { Acid Clavulanic }\end{array}$ & 24 & 36,9 & \multirow{4}{*}{100} \\
\hline & Macrolid & 12 & 18,5 & \\
\hline & $\begin{array}{l}\text { Nhóm kháng } \\
\text { sinh khác }\end{array}$ & 6 & 9,2 & \\
\hline $\begin{array}{l}\text { Chưa } \\
\text { dùng }\end{array}$ & & 23 & $\begin{array}{c}35 \\
4\end{array}$ & \\
\hline
\end{tabular}


Nhận xét: Tỷ lệ sử dụng kháng sinh trước vào việ̉n cao $(64,6 \%)$. Trong đó hầu hết là sử dụng kháng sinh Amoxcicilin/Amoxcicilin + Acid Clavulanic và Macrolid $(55,4 \%)$.

Bảng 3.3. Đặc điểm lâm sàng và cận lâm sàng của viêm phổi cộng đồng do S.Pneumoniae

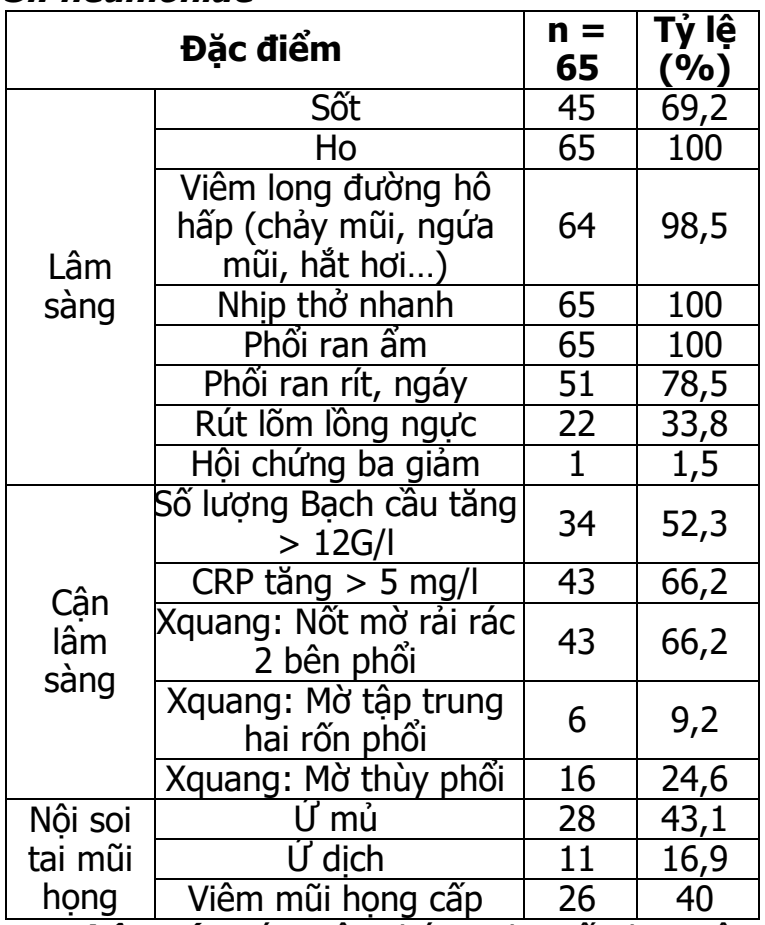

Nhận xét: Các triệu chứng như sốt, ho, viêm long đường hô hấp, phổi có ran gặp tỷ lệ cao trên $69 \%$. Tỷ lệ bệnh nhân có Bạch câu tăng là $52,3 \%$; có CRP tăng > 5mg/L là $66,2 \%$. 24,6\% trẻ có hình ảnh viêm phổi thùy trên Xquang còn lại hầu hết là tình trạng nốt mờ rải rác 2 bên phổi $(66,2 \%) .60 \%$ bệnh nhân kèm theo viêm tai giữa, chủ yếu là viêm tai giữa ứ mủ $(43,1 \%)$.

Bảng 3.4. Mức nhạy cảm kháng sinh của S.Pneumoniae

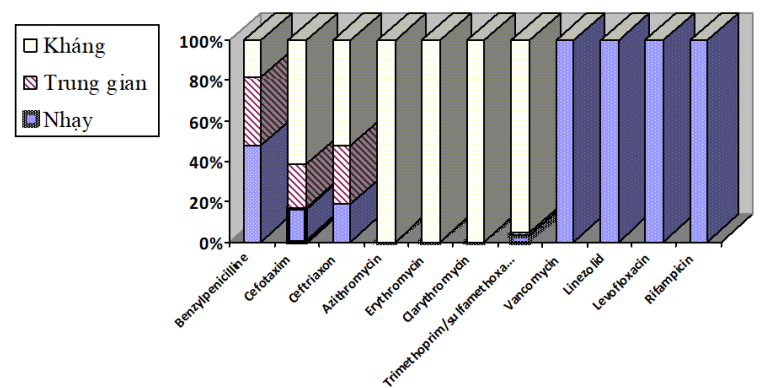

Nhận xét: S.Pneumoniae nhạy cảm $100 \%$ với kháng sinh Linezolid, Vancomycin, Rifampicin. Nhạy cảm tương đối với Benzylpenicilline
$(81,5 \%)$, nhạy cảm ít với Cefotaxime $(16,9 \%)$, Ceftriaxone $(18,5 \%)$. Kháng hoàn toàn $(100 \%)$ với nhóm kháng sinh Macrolide, kháng gần như hoàn toàn với Trimethoprim/Sulfamethoxazole $(95,4 \%)$.

\section{BÀN LUÂNN}

Nghiên cứu của chúng tôi thực hiện trên 65 bệnh nhân từ 1 tháng đến dưới 5 tuổi bị viêm phổi do S.Pneumoniae tại bệnh viện Sản Nhi Nghệ An. Chúng tôi thây rằng viêm phổi do S.Pneumoniae gặp nhiều nhất ở nhóm tuổi 2 tháng - dưới 24 tháng (76,9\%), ít gặp ở nhóm tuổi dưới 2 tháng $(9,2 \%)$. Theo Vijayakumary (2021) nhiễm trùng do S.Pneumoniae thường xảy ra ở trẻ em dưới năm tuổi và phổ biến hơn ở trẻ em dưới hai tuổi. Trẻ em ở những lứa tuổi này dễ bị nhiễm trùng hơn do hệ miễn dịch chưa hoàn thiện. Trong ba tháng đầu đời, trẻ ít bị nhiễm S.Pneumoniae hơn vì được bảo vệ bởi các kháng thể từ sữa me và nhau thai một cách thụ động [3]. Tỷ lệ Nam/ Nữ là 1,9/1 tương đồng với kết quả của các nghiên cứu khác [4],[5]. Về biểu hiện lâm sàng các các triệu chứng như sốt, ho, viểm long đường hô hấp , phổi có ran gặp tỷ lệ cao trên $69 \%$. Triệu chứng của viêm phổi nặng như rút lõm lồng ngực chiếm tỷ lê $33,8 \%$. Tỷ lê bệnh nhân có Bạch cầu tăng là $52,3 \%$; có CRP tăng > 5mg/L là $66,2 \%$ phản ánh tình trạng nhiểm trùng khi vi khuẩn xâm nhập cơ thể. Có $24,6 \%$ có hình ảnh viêm phổi thùy trên Xquang còn lại hầu hết là tình trạng viêm phế quản phổi $(66,2 \%)$. Nghiên cứu của chúng tôi tương tự như kêt quả của các nghiên cứu khác [6],[7].

S.Pneumoniae cũng là nguyên nhân chủ yếu gây viêm tai giữa cấp tính và cũng là một căn nguyên hay gây viêm tai giữa dai dẳng, tái phát [3]. Trong nghiên cứu của chúng tôi, có đến $60 \%$ bệnh nhân viêm phổi kèm viêm tai giữa được chẩn đoán qua nội soi tai mũi họng, trong đó chủ yếu là viêm tai giữa ứ mủ $(43,1 \%)$. Vì thế nên tiến hành nội soi tai mũi họng để phát hiện bênh viêm tai giữa phối hợp ở các bênh nhẩn viêm phổi do S.Pneumoniae. Từ đó có kế hoạch theo dõi, tránh những biến chứng đáng tiếc có thể xảy ra như ảnh hưởng đến thính lực, viêm màng não mủ do viêm tai giữa, ... nếu bị bỏ sót.

Chúng tôi cũng nhận thấy rằng, một tỷ lệ tương đối lớn bệnh nhân trong nghiên cứu của chúng tôi đã sử dụng kháng sinh trước vào viện $(64,6 \%)$. Trong đó hầu hết là sử dụng kháng sinh Amoxcicilin/Amoxcicilin + Acid Clavulanic và Macrolid (55,4\%). Kết qủa này tương tự như kết quả của Nguyễn Thị Thu Huyền [4]. Trước đây, 
hầu hết các chủng S.Pneumoniae đều nhạy cảm với kháng sinh beta-lactam (cephalosporin, penicillin) và macrolide. Nhưng gân đây, tình trạng kháng thuốc ngày càng gia tăng đã được quan sát thấy ở hầu hết các khu vực, đặc biệt là các khu vực sử dụng nhiều kháng sinh. Tuy nhiên hầu hết các khu vực trên thế giới, S.Pneumoniae vẫn còn nhạy cảm với Vancomycin [2]. Nghiên cứu của chúng tôi thấy rằng các chủng S.Pneumoniae phân lập được tại Bệnh viện Sản Nhi Nghệ An nhạy cảm $100 \%$ với kháng sinh Linezolid, Vancomycin, Rifampicin. Nhạy cảm tương đối với Benzylpenicilline, nhạy cảm ít với Cefotaxime (16,9\%), Ceftriaxone $(18,5 \%)$. Đặc biệt, các chủng S.Pneumoniae phân lập được đã kháng hoàn toàn (100\%) với nhóm kháng sinh Macrolide, kháng gần như hoàn toàn với Trimethoprim/Sulfamethoxazole $(95,4 \%)$. Kết quả này tương tự như kết quả của nhiều nghiên cứu khác đã được báo cáo trước đây [4],[6],[7]. Đây là một đặc điểm quan trọng bởi vì các kháng sinh nhóm Macrolide như Azithromycin, Erythromycin, Clarythromycin rất thông dụng khi các bác sỹ kê đơn ngoại trú thì mức độ kháng rất cao, từ đó ảnh hưởng rất lớn đến hiệu quả điều trị.

\section{KẾT LUÂ̂N}

Qua nghiên cứu 65 trẻ dưới 5 tuổi viêm phổi cộng đồng do S.Pneumoniae tại Bệnh viện Sản Nhi Nghệ An chúng tôi thây rằng: Tỷ lệ Nam/Nũ̃ là: $1,9 / 1$. Lứa tuổi hay gặp nhất là 2 tháng -24 tháng (76,9\%). Tỷ lệ bệnh nhân đã dùng kháng sinh trước vào viện cao, chiếm $64,6 \%$, chủ yếu là nhóm Amoxcicilin/Amoxcicilin + Acid Clavulanic và Macrolid. Các triệu chứng như sốt, ho, chảy nước mũi, thở nhanh, phổi có ran gặp tỷ lệ > 69\%. Viêm tai giữa ứ mủ gặp 43,1\% trẻ em dưới 5 tuổi viêm phổi do S.Pneumoniae. S.Pneumoniae kháng hoàn toàn với Azithromycin, Clarithromycin, Erythromycin; kháng với Cefotaxime là $61,5 \%$, Ceftriaxone là $52,3 \%$, Penicillin là $18,5 \%$. S.Pneumoniae còn nhạy $100 \%$ với Rifampicin, Vancomycin, Linezolid, Levofloxacin.

\section{TÀI LIẸU THAM KHẢO}

1. Achamyelesh Geberetsadik (2015). Factors associated with acute respistory infection in children under the age of 5 years: evidence from the 2011 Ethiopia Demographic and Health Survey. Pediatric Health Med Ther, 6:9-13.

2. Đặng Đức Anh (2004). Tỷ lệ nhiễm H.Influenzae, S.pneumonia và các vi rút hô hấp ở bênh nhân dưới 5 tuổi viêm đường hô hấp cấp. Tạp chí y học dự phòng, số 4 (68).

3. Vijayakumary T. and Kavinda D. (2021) Review on Pneumococcal Infection in Children. Cureus. 13(5): e14913.

4. Nguyễn Thị Thu Huyền, Lê Thị Hî̀ng Hanh và cống sự (2020). Đặc điểm dịch tể học lâm sàng và kết quà điều tri viềm phổi do phế cầu ở trẻ em dưới 5 tuổi tại bệnh viện Trung Ương Thái Nguyên. Tỷ lệ nhiểm H.Influenzae, S.pneumonia và các vi rut hô hấp ở bênh nhân dưới 5 tuổi viêm đường hô hấp cấp. Tạp chí y học Viêtt Nam, số 18.2, tr71 - 74.

5. Nguyên Thi Diêu Thứy (2018). Nguyên nhân gây viêm phổi ở trẻ em điêu trị tại khoa điều trị tự nguyên $B$ Bênh viện Nhi Trung Ương. Tạp chí ỳ hoc thực Viêt Nam, số 468, tr126 - 129.

6. Đăng Thị Thùy Dương (2018). Nghiên cứu đặc điểm lâm sàng, cân lâm sàng theo căn nguyên vì khuẩn gây viêm phổi ở trẻ em dưới 5 tuổi tại bệnh viện Nhi Thái Bình, Luận văn Thạc sỹ Ỳ học, Trường Đại học Y Hà Nội.

7. Lê Thanh Duyên (2017). Đắc điểm lâm sàng và tính nhay cảm kháng sinh của Streptococcus Pneumoniae gây viêm phổi cộng đồng ở trẻ em tại Hải Dương. Tap chí Y học Việt Nam, số tháng 6 2017, tr160 - 163.

\section{KẾT QUẢ PHẪU THUÂTT Cố ĐINNH VÀ GIẢI ÉP CộT SốNG LỐI SAU TRONG CHẤN THƯƠNG CộT SỐNG Cổ THẤP Có LIÊTT TỦY}

\section{TÓM TẮT}

\author{
${ }^{1}$ Bệnh viện đa khoa tỉnh Bắc Giang \\ 2Trường Đại học Y Hà Nội \\ ${ }^{3}$ Bênh viên Hữu Nghi Việt-Đức \\ Chịu trách nhiệm chính: Nguyễn Hoàng Long \\ Email: longptcs@gmail.com \\ Ngày nhận bài: 27.7.2021 \\ Ngày phản biên khoa họ: 28.9.2021 \\ Ngày duyệt bài: 4.10 .2021
}

\section{Mạc Hoàng Dương ${ }^{1}$, Hà Kim Trung ${ }^{2}$, Nguyễn Hoàng Long ${ }^{3}$}

Nghiên cứu mô tả hồi cứu 60 bệnh nhẫn chấn thương cột sống cổ thấp có liệt tủyđược phẫu thuật bằng phương pháp mổ lối sau tại Bệnh viện Hữu nghi Việt Đức nhằm mô tả các đặc điểm dịch tễ học, nguyên nhân, một số đặc điểm lâm sàng và kết quả điêu trị. Tuổi trung bình của đối tượng nghiên cứu là $52,92 \pm 14,84$ chiếm $65 \%$ trong độ tuổi lao động. Trong60 đối tượng nghiên cứu, nam giới chiếm 88,3\% và có $4 / 5$ đối tượng tử vonglà nam giới. Tỷ lệ bệnh nhân có rối loan cớ tròn trước khi phẫu thuật là $91,7 \%$ và sau khi phẩu thuật giảm còn $67,9 \%$, sự cải thiện có ý nghĩa thống kê về tỳ lệ hồi phụcchức năng cớ tròn 